\title{
Estudo ecogeográfico da poaia [Psychotria ipecacuanha (Brot.) Stokes]
}

\author{
MARTINS, E.R. ${ }^{1}$; OLIVEIRA, L.O. ${ }^{2}$; MAIA, J.T.L.S. ${ }^{{ }^{*}}$; VIEIRA, I.J.C. ${ }^{2}$ \\ Instituto de Ciências Agrárias, Universidade Federal de Minas Gerais - Cx. Postal 135 - CEP 39.404-006 - Montes \\ Claros, MG; *janinitatimaia@yahoo.com.br ${ }^{2}$ Universidade Federal de Viçosa - CEP 36571000 -Viçosa, MG
}

\begin{abstract}
RESUMO: Este estudo foi conduzido com 13 populações amostradas nos estados RJ, MG, ES e BA para a coleta de dados ecogeográficos da poaia (Psychotria ipecacuanha). Foi conduzida a análise de freqüência de ocorrência de características ambientais, tais como: altitude, pluviosidade, temperaturas máxima, média e mínima absolutas, latitude e longitude. A análise etnobotânica consistiu no levantamento de formas terapêuticas, homeopáticas e as crendices relacionadas à utilização da poaia. Os teores dos alcalóides emetina e cefelina foram determinados, utilizandose cromatografia líquida de alta eficiência (CLAE). Aproximadamente $87 \%$ das reboleiras ocorreram emsolo distrófico. Dentre os micronutrientes analisados, $\mathrm{Fe}, \mathrm{Mn}$, e Cu apresentaram correlações significativas comnúmero de hastes por reboleira $(\mathrm{NH})$ e peso de raízes secas $(\mathrm{PR})$. O comprimento, em $65 \%$ das reboleiras, foi inferior a $2 \mathrm{~m}$, sendo que as dimensões médias das reboleiras foram de 1,8 x 1,3 m. A porcentagem da radiação fotossiteticamente ativa variou entre 0,14 e $17 \%$. Dos locais onde ocorreram as reboleiras, cerca de $69 \%$ foram consideradas compequena inclinação. A caracterização química revelou que em cerca de $65 \%$ das amostras de raízes analisadas, foram observados teores de emetina entre 1 e $2 \%$, e o teor de cefelina, em $61 \%$ das amostras, foi inferior a $0,3 \%$. As características morfológicas e químicas foramanalisadas pela técnica de componentes principais, concluindo-se que os resultados obtidos são pouco informativos sobre a diversidade genética, possibilitando o descarte de características cuja variação é pequena e, também, aquelas altamente correlacionadas entre si.
\end{abstract}

Palavras-chave: Psychotria ipecacuanha, emetina, cefelina

\begin{abstract}
Ecogeographic study of "poaia" Psychotria ipecacuanha (Brot.) Stokes. This study included 13 populations sampled in the states Rio de Janeiro, Minas Gerais, Espírito Santo, and Bahia, to collect ecogeographic data of "poaia" (Psychotria ipecacuanha). Frequencyof-occurrence analysis consisted of the following environmental characteristics: altitude, rainfall, maximum, medium and minimum absolute temperatures, latitude and longitude. Ethnobotanical analysis consisted of a survey on therapeutic and homeopathic forms, as well as on the popular knowledge related to "poaia" use. The levels of the alkaloids emetine and cephaeline were determined using high performance liquid chromatography (HPLC). Nearly $87 \%$ shrubs occurred in dystrophic soil. Among the evaluated micronutrients, $\mathrm{Fe}, \mathrm{Mn}$ and Cu presented significant correlations with stem number per shrub (SN) and dry root weight (RW). The length of $65 \%$ shrubs was lower than $2 \mathrm{~m}$, and mean dimensions were $1.8 \times 1.3 \mathrm{~m}$. The photosynthetically active radiation percentage ranged from $0.14 \%$ to $17 \%$. Concerning the places where shrubs were found, around $69 \%$ were considered of low inclination. Root chemical characterization indicated 1 and $2 \%$ emetine content in approximately $65 \%$ analyzed samples, and less than $0.3 \%$ cephaeline in $61 \%$ samples. Morphologic and chemical characteristics were analyzed by the principal component technique. In conclusion, the obtained results are low informative regarding genetic diversity, which allows the discard of characteristics presenting small variation and those highly correlated.
\end{abstract}

Key words: Psychotria ipecacuanha, emetine, cephaeline

Recebido para publicação em 26/09/2007

Aceito para publicação em 15/09/2008

Rev. Bras. PI. Med., Botucatu, v.11, n.1, p.24-32, 2009. 


\section{INTRODUÇÃO}

A poaia (Psychotria ipecacuanha) é uma espécie medicinal brasileira, da família Rubiaceae, que passou por intenso extrativismo (coleta de raízes) e redução do seu hábitat. É utilizada comercialmente desde o século XVIII, sem que houvesse replantio ou manejo adequado das áreas de coleta (Assis, 1992), indicando que parte de sua variabilidade genética pode ter sido perdida, principalmente nos locais onde houve coleta intensa. A mata atlântica é um destes locais que, apesar de ter passado por extrativismo intenso e ter sua área reduzida, ainda apresenta populações remanescentes desta espécie.

O centro de origemda espécie é provavelmente o continente americano (Oliveira \& Martins, 1998). De acordo comAssis (1992), a ocorrência de poaia nativa se restringe a três regiões distintas: nos países da América Central, no Norte da América do Sul (Colômbia), no sul da Amazônia brasileira (estados de Mato Grosso e Rondônia) e na Mata Atlântica (principalmente nos estados de Minas Gerais, Espírito Santo, Rio de Janeiro e Bahia). De acordo com Pinto (1972), a poaia ocorre em matas pluviais com precipitação anual em torno de 2000 mm, temperatura média em torno de $25^{\circ} \mathrm{C}$ e umidade relativa do ar média de $80 \%$. Veloso (1947) destaca que a topografia e a inclinação do terreno, o grau de acidez dos horizontes superficiais do solo, a qualidade da drenagem, a natureza física do solo e a porcentagem do tipo de cobertura vegetal das áreas estudadas influenciama ocorrência da espécie.

$\mathrm{Na}$ poaia os constituintes químicos mais ativos são os alcalóides isoquinolínicos: emetina, cefelina e psicotrina (Sahu \& Mahato, 1982; Sousa et al., 1991). A emetina é altamente solúvel em metanol, etanol, acetona, acetato de etila, clorofórmio e éter (Costa, 1978). A cefelina é um dos principais responsáveis pela atividade emética, com pequena atividade amebicida (Sousa et al., 1991; Costa, 1978).

O estudo ecogeográfico é um processo de obtenção e síntese de informações ecológicas, geográficas e taxonômicas, sendo os seus resultados preditivos, podendo ser usados na formulação de estratégias de conservação e prioridades de coleta (Maxted et al., 2000). Um importante trabalho com ecogeografia e coleta de recursos genéticos foi conduzido por Cristiansen et al. (1999) coma espécie Lupinus albus, planta alimentícia e medicinal do Egito encontrada próximo a fazendas, sendo reunidas informações tais como: análise química e física do solo, práticas agrícolas locais, morfologia da planta, teor de alcalóides e ocorrência de infecção com Fusarium. Os resultados evidenciarama existência de ecótipos tolerantes a pH muito básico e grande variação na ocorrência do fungo, teor de alcalóides, nos hábitos de crescimento, arquitetura, vigor das plantas e cor de suas flores.
Diante do exposto, o presente trabalho tem como objetivo caracterizar os locais de ocorrência de populações de poaia, quanto ao solo, morfologia da planta e porcentagem de radiação fotossinteticamente ativa, bem como os níveis de alcalóides nas raízes, além de levantar os dados etnobotânicos e os aspectos culturais envolvidos na sua utilização.

\section{MATERIALE MÉTODO}

$\mathrm{Na}$ coleta dos dados foram empreendidas viagens ao campo, nos anos de 1996-1999, como objetivo de localizar populações de poaia ( $P$ sychotria ipecacauanha Standl.), coletar germoplasma e obter informações etnobotânicas. O destino das viagens foi orientado pelas informações fornecidas por populares (Conceição de Macabu-RJ, Itaperuna-RJ, Irupi-RJ, Eugenópolis-MG, Muriaé-MG, Vieiras-MG, Visconde do Rio Branco-MG, Mariléa-MG, São Pedro dos Ferros-MG, Marilac-MG e Ibicaraí-Ba), pela presença de fragmento florestal das diversas formações de vegetação que compõe a Mata Atlântica (Campos dos Goytacazes-RJ, Macaé-RJ, Silva Jardim-RJe Carangola-MG) e informação de exsicata de $P$. ipecacauanhadepositada emherbários (Pontes e Lacerda-MT, Caratinga-MG, Natividade/PorciúnculaRJ e Una-BA).

Uma vez localizadas as reboleiras da poaia, iniciava-se o procedimento de coleta, principalmente de coleta, primeiramente buscando levantar informações para subsidiar o trabalho ecogeográfico. As informações levantadas inicialmente eramem duas hierarquias: local abrangendo uma ou mais reboleiras, e de reboleira, envolvendo número variável de hastes. As observações realizadas foram: latitude, longitude e altitude, utilizando o Receptor GPS, marca Garmin, modelo GPS38; informações etnobotânicas e culturais; presença de frutos e flores (se brevistilas ou longistilas); número de hastes, dimensões e inclinação do local onde se encontra a reboleira ou fogão da reboleira (nome popular dado a reboleira), podendo ser alta média e baixa; porcentagem da radiação fotossinteticamente ativa ou fluxo de fótons fostossintéticos, utilizando o Fotômetro, marca licor, modelo Li189, com sensor "Quantum" Li190SA; análises granulométricas e químicas dos solos.

Não houve qualquer sistemática na seleção de indivíduos (reboleiras) a serem coletados, praticamente todos os que foram observados foram amostrados, à exceção dos casos em que a disponibilidade de tempo ou a capacidade de trabalho limitaram a coleta. Assim, entre 1 a 3 reboleiras foram amostradas em cada local. Por fim, eram coletadas as hastes comraízes. O número de hastes retiradas por reboleira variou entre uma e cinco, evitando-se a coleta excessiva e, portanto, minimizando os danos à população. As amostras foram embaladas em sacos 
plásticos e transportadas ao laboratório em caixas de isopor ou bolsas térmicas, onde foi feita a determinação da altura (parte aérea), número de nós (parte ereta da haste), peso seco das raízes (à temperatura de $25^{\circ} \mathrm{C}$ ), número de folhas, comprimento e largura das folhas (área foliar) e diâmetro da base da haste. As raízes secas foram utilizadas na extração e determinação do teor dos alcalóides emetina e cefelina.

Para se estimar a área de cada folha, foi necessário o ajuste de uma regressão múltipla, envolvendo a área foliar real, determinada emmedidor de área foliar Licor, modelo Li-3100, e o comprimento e largura de cada uma das 34 folhas utilizadas no ensaio (Figueiredo, 1998). A área foliar da haste foi obtida por meio da soma da área de cada folha presente na mesma.

As amostras de solo, representativas de cada reboleira, foram encaminhadas para análises granulométrica (Laboratório de Análise de Solos da FUNDENOR, em Campos dos Goytacazes-RJ) e de fertilidade ou química (Laboratório de Análise de Solos da Universidade Federal de Viçosa, em Viçosa - MG).

A determinação dos teores de cefelina e emetina foi realizada por meio da cromatografia líquida de alta eficiência (CLAE). As amostras de raízes de cada haste coletada, após serem pulverizadas em almofariz de porcelana, foram colocadas cerca de 80 a $100 \mathrm{mg}$ emfrasco plástico de centrífuga (tipo falcon), sendo que, a cada frasco, adicionou-se $2 \mathrm{~mL}$ de $\mathrm{NaOH}$ $(0,1 \mathrm{M})$, que foi mantido sob agitação por $1 \mathrm{~min}$. Posteriormente, $10 \mathrm{~mL}$ de éter etílico foram adicionados à emulsão que foi novamente submetida à agitação por $5 \mathrm{~min}$. Essa mistura foi centrifugada a $4500 \mathrm{rpm}$ por $5 \mathrm{~min}$. A fase etérea foi coletada e depositada em frascos âmbar. A fase aquosa foi extraída por duas vezes e as fases orgânicas resultantes foram reunidas e evaporadas até a secura, resultando no extrato final. As condições de trabalho para a realização da CLAE foram as seguintes: fase móvel - tampão acetato pH 5,0 / 0,25 N acetonitrila (8:5); coluna - Shimadzu modelo Shimpack ODS18, (20 mL / $25 \mathrm{~cm} \times 4,6 \mathrm{~mm}$ ); fluxo de 0,5 mL min-1, comprimento de onda de $288 \mathrm{~nm}$.

Objetivando estimar correlações simples entre características morfológicas e químicas da raiz, foi conduzido ensaio onde se determinou a concentração de emetina e cefelina emamostras de raízes com várias espessuras em dois acessos. Foram utilizadas amostras de raízes dos acessos: UNA-1 e ITAP-1 provenientes de Una-BAe ItaperunaRJ (Tabela 1). Analisaram-se 19 amostras de raízes de cada acesso, determinando-se o diâmetro externo, o cilindro central (xilema) e porcentagem de peso deste cilindro em relação ao peso total da amostra, submetendo-se os dados à análise de correlações simples.
Os dados foram coletados em três hierarquias: local ou população, reboleira (s) ou acessos emcada locale haste (s) emcada reboleira. Os dados obtidos ao nível de haste foram transformados em médias por reboleira. A partir dos dados de posição (latitude e longitude) do local de coleta, foram utilizados mapas climáticos (Nimer, 1989) e de vegetação (Instituto Brasileiro de Geografia e Estatística, 1993). Foi conduzida análise de freqüência e análise de correlação simples quanto a local e reboleira (incluindo-se médias das medidas tomadas nas hastes). As correlações simples foram obtidas pelo confronto dos dados médios morfológicos, químicos e ambientais (teores de cefelina e de emetina, número de hastes, altura de hastes, número de nós, número de folhas e peso das raízes).

\section{RESULTADO E DISCUSSÃO}

O estudo foi conduzido considerando apenas 13 populações amostradas nos estados RJ, MG, ES e BA (Tabela 1), uma vez que não foi possível o deslocamento até Ponte e Lacerda-MT para coletar dados ecogeográficos. Os valores mínimos e máximos e as faixas de maior freqüência de ocorrência das características altitude, pluviosidade, temperaturas máxima absoluta, média e mínima absoluta, latitude e longitude nas 13 populações, estão dispostos na Tabela 1. Cerca de $70 \%$ das populações foram localizadas entre 200 e $600 \mathrm{~m}$ de altitude, concordando com Torres (1972), que informa que o gênero Cephaelis (muitas espécies pertencentes a este gênero foram incluídas no gênero Psychotria) tem ocorrência mais freqüente em altitudes inferiores a 800-1000 m.

Uma abrangência geográfica (Tabela 1) permitiu e amostrar e comparar populações distantes entre si em $800 \mathrm{Km}$. Como por exemplo, o acesso VRB1, embora fisicamente próximo da população VRB2-3 (cerca de $4000 \mathrm{~m}$ ), tinha origem diferente destes de acordo com informação obtida no local, mas esta distância não pôde ser determinada, pela ausência de exatidão da informação do local correto de origem. Cerca de $85 \%$ dos acessos estavam localizados entre 18 e $22^{\circ}$ de latitude sul, e cerca de $92 \%$ dos acessos apresentavam longitude oeste entre 41 e 43ํㅡㅇ o que é uma área razoável com inúmeros fragmentos de Mata Atlântica, os quais merecem ser investigados buscando novas populações de poaia.

A pluviosidade dos locais de coleta foi de 1250 e 1500 mm, com predomínio da primeira, com temperaturas mínima absoluta, média e máxima variando entre 0 e $8^{\circ} \mathrm{C}, 20$ e $22^{\circ} \mathrm{C}$ e entre 36 e $38^{\circ} \mathrm{C}$, respectivamente. Tais resultados estão bem abaixo daquelas observadas por Torres (1972), que informaram temperaturas médias entre 22 e $28^{\circ} \mathrm{C}$ e 
precipitação anual que varia entre 1600-1800 e 4000 $\mathrm{mm}$, na área de ocorrência da Colômbia, possivelmente porque as observações do autor se referem às vastas áreas de Floresta Tropical Pluvial.

Avegetação predominante em dezlocais de coleta (exceto UNA, CON e MAR) (Tabela 1), segundo - Mapa de Vegetação do Brasil (Instituto Brasileiro de Geografia e Estatística, 1993), é a Floresta Tropical Subcaducifólia (com duas estações, uma seca e outra chuvosa), em áreas de vegetação tipicamente secundária. A população UNA foi encontrada numa Restinga Arbórea, ao lado de uma área de tensão ecológica (Cerrado e Floresta Tropical Pluvial). A população CON está situada em uma área de transição entre a Floresta Ombrófila Densa Montana (com dois meses de umidade escassa) e Floresta Tropical Subcaducifólia, e a população MAR, nos domínios da Floresta Ombrófila Densa Submontana, próximo a áreas com vegetação secundária da Floresta Tropical Subcaducifólia.

O clima tropical quente semi-úmido, com 45 meses secos é característico das populações CAT, ITA, MUR e EUG. Já o clima sub-quente semi-úmido, com 4-5 meses secos é representado pelas populações CAR, MAR, VRB1, VRB2-3 e VRB4-6. A população UNA possui clima mediterrâneo quente super-úmido, enquanto a população CON têm clima quente úmido, com 1 a 2 meses secos. O clima mesotérmico brando úmido, com 3 meses secos é característico da população IRU. As áreas cujo clima apresenta 4 a 5 meses secos, correspondem principalmente àquelas com Floresta Estacional Semidecidual, cuja caracterização inclui uma estação seca e outra chuvosa, à exceção de MAR, que apresenta Floresta Ombrófila Densa Submontana, onde se espera dois meses secos. No entanto, esta última população está emárea próxima à transição para o primeiro tipo de floresta. Assim, a diferenciação climática apresentou alta coerência com o tipo de vegetação presente, como esperado.

Apresença de frutos maduros foi observada nas populações MAR e ITA (meados de maio), UNA (meados de janeiro), VRB4-6 (final de janeiro) e CON (final de junho), indicando duas épocas de frutificação: início e meio do ano. Plantas em plena floração foram detectadas nas populações CAT, CAR e ITA entre dezembro e janeiro, o que está de acordo com Assis (1992), que constatou frutificação em fevereiro, abril e julho em espécimes da Mata Atlântica e floração, na Bahia, em junho-julho; em Minas Gerais, o início da floração se deu entre outubro e novembro.

TABELA1. Caracterização macroclimática dos locais de ocorrência de populações de poaia (Psychotria ipecacuanha) coletadas no sudeste brasileiro

\begin{tabular}{|c|c|c|c|c|c|c|c|c|c|}
\hline Município & 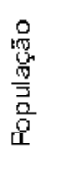 & $\begin{array}{l}0_{0} \\
0 \\
8 \\
0 \\
0 \\
\mathbb{1}\end{array}$ & $\begin{array}{l}\frac{0}{\mathrm{O}} \\
\frac{\vec{E}}{\mathrm{E}}\end{array}$ & $\begin{array}{l}\frac{w}{5} \\
\frac{1}{+} \\
\frac{5}{9} \\
\frac{5}{9}\end{array}$ & 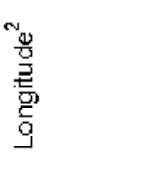 & 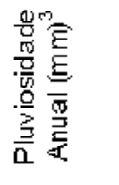 & 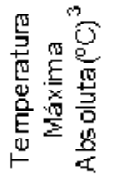 & 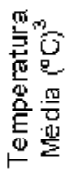 & 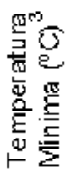 \\
\hline Carangola - MG & CAR & 1,2 e 3 & 300 & $520^{\circ} 45$ & W04 Z 03 & 1250 & 36 & 22 & 0 \\
\hline Caratinga - MG & CAT & $1,2 \in 3$ & 450 & $\mathrm{~S} 19^{\circ} 44^{\prime}$ & $W 041^{\circ} 4 g^{\prime}$ & 1250 & 36 & 20 & 0 \\
\hline $\begin{array}{l}\text { Conce içāo de } \\
\text { Macabu - RJ }\end{array}$ & CON & 1,2 e 3 & 260 & $522^{\circ} 04^{\prime}$ & WO4 $11^{\circ} 53^{\prime}$ & 1250 & 40 & 20 & 4 \\
\hline Eugenopolis -MG & EUG & 1 & 320 & $S 21^{\circ} 04^{\prime}$ & WO42 13 & 1250 & 40 & 20 & 4 \\
\hline Irupi - ES & IRU & 1 & 890 & $\mathrm{~S} 20^{\circ} 22^{\prime}$ & WO41038 & 1250 & 38 & 18 & 0 \\
\hline Itaperuna - RJ & ITA & $1,2 e^{3}$ & 190 & $S 21^{\circ} 07$ & W042 $02^{\circ}$ & 1250 & 42 & 22 & 4 \\
\hline Marilac - MG & MAC & 1 & 120 & $\$ 18^{\circ} 28^{\circ}$ & W042010: & 1250 & 38 & 20 & 4 \\
\hline Marliéria - MG & MAR & $1 e 2$ & 300 & $519^{\circ} 46^{\prime}$ & WO42038: & 1250 & 36 & 20 & 0 \\
\hline Muriaé - MG & MUR & 1 & 260 & $\$ 21^{\circ} 05$ & WO42 19 & 1250 & 40 & 20 & 4 \\
\hline Una - BA & UNA & 1 e 2 & 0 & $515^{\circ} 18^{\circ}$ & W039०00 & 1500 & 36 & 24 & 8 \\
\hline \multirow{3}{*}{$\begin{array}{l}\text { Visconde do Rio } \\
\text { Branco - } \mathrm{MG}^{4}\end{array}$} & VRB & 1 & 400 & $320^{\circ} 59$ & WO42055: & 1250 & 36 & 20 & 0 \\
\hline & $\begin{array}{l}\text { VRB } \\
2-3\end{array}$ & 1 & 480 & $S 20^{\circ} 59^{\prime}$ & W042055 & 1250 & 36 & 20 & 0 \\
\hline & $\begin{array}{l}\text { VRB } \\
4-6\end{array}$ & 1 & 390 & S20 $58^{\circ}$ & WO42053 & 1250 & 36 & 20 & 0 \\
\hline
\end{tabular}

${ }^{1}$ Obtida por meio de receptor GPS e, ou, de altímetro digital. ${ }^{2}$ Obtido por meio de receptor GPS. ${ }^{3}$ Determinada após plotagem em mapas fornecidos por Nimer (1989). ${ }^{4} \mathrm{Na}$ mesma viagem foram localizadas três populações geograficamente distintas, sendo uma cultivada e duas silvestres. 


\section{Etnobotânica e cultura}

Comrelação ao uso terapêutico da espécie nos locais de coleta, observou-se que este ocorria apenas nas vizinhanças dos locais ou populações: MAC, MUR, EUG, VRB1, VRB2-3 e VRB4-6. O principal uso está relacionado à preparação de fitoterápicos, além do uso homeopático com indicações para desordens do aparelho respiratório.

Crendices relacionadas à coleta da poaia, como a grande probabilidade de se encontrarem serpentes venenosas próximo às reboleiras da espécie, revelaram talvez uma herança das dificuldades enfrentadas pelos poaeiros antigos, que tinham as cobras como principais inimigos.

\section{Caracterização do solo}

Aproximadamente $87 \%$ das reboleiras ocorreram em solo distrófico $(\mathrm{V} \%<50)$, dentre estes, $59 \%$ foram considerados álicos ( $m>50$ e $\mathrm{Al}>0,3$ ) isto é, muito pobres. A saturação de $\mathrm{Al}$ na CTC efetiva $(m)$ foi de média a muito alta, sendo positiva a correlação feita com o teor de emetina (E). Da mesma forma, correlações negativas foram observadas entre $\mathrm{E}$ e $\mathrm{pH}, \mathrm{Mg}, \mathrm{SB}$ e V\%, conforme Tabela 2. O número de hastes por reboleira $(\mathrm{NH})$ foi positivamente correlacionado como teor de $\mathrm{Mg}$, $\mathrm{V} \%$ e SB, o inverso ocorrendo com $\mathrm{H}+\mathrm{Al}$ e $\mathrm{m}$ (correlação não significativa, mas negativa). As limitações que foram observadas na maioria dos locais de coleta normalmente prejudicam o metabolismo primário, ligado à produção de biomassa, mas podem ter efeito inverso sobre o metabolismo secundário (Oliveira \& Martins, 1998). As características químicas do solo e correlações

TABELA 2. Características químicas e físicas do solo com as correlações simples, porcentagem de radiação fotossinteticamente ativa (RFA), número de hastes por reboleira $(\mathrm{NH})$, número de nós - NN, altura - $\mathrm{A}$, número de folhas - NF, diâmetro do caule - DC, peso de raízes secas - PR, área foliar - (AF), posição dos locais de coleta (latitude - Lat, longitude - Long, altitude - Alt), peso de raízes secas (PR), número de hastes por reboleira (NH), teores de cefelina (C) e emetina (E) em 26 acessos de Psychotria ipecacuanha coletados nos estados: RJ, ES, MG e BA.

\begin{tabular}{|c|c|c|c|c|c|c|c|}
\hline \multicolumn{3}{|c|}{ Características } & Médiatdp ${ }^{1}$ & $C(n=26)$ & $E(n=26)$ & $\mathrm{NH}(\mathrm{n}=26)$ & $\mathrm{PR}(\mathrm{n}=26)$ \\
\hline \multirow{11}{*}{$\frac{\sqrt[6]{5}}{\frac{5}{8}}$} & $\mathrm{pH}$ em H $\mathrm{H}_{2} \mathrm{O}$ & \multirow{3}{*}{$\mathrm{mg} \mathrm{dm}$} & $4,65 \pm 0,67$ & $-0,06$ & $-0,46^{*}$ & 0,21 & 0,00 \\
\hline & $P$ & & $3,90 \pm 1,95$ & 0.18 & $-0,26$ & $-0,35$ & 0,12 \\
\hline & $\mathrm{k}^{+}$ & & $37,3 \pm 17,5$ & $-0,03$ & $-0,13$ & 021 & $-0,02$ \\
\hline & $\mathrm{Ca}^{24}$ & \multirow[t]{7}{*}{$\mathrm{cmol}{ }_{\mathrm{c}}^{3} \mathrm{dm} \mathrm{m}^{-3}$} & $1,24 \pm 1,25$ & 0.06 & $-0,38$ & 0.25 & $-0,13$ \\
\hline & $\mathrm{Mg}^{21}$ & & $0,69 \pm 0,74$ & 0,05 & $-0,40^{*}$ & $0,40^{*}$ & $-0,10$ \\
\hline & $\mathrm{Al}^{3 *}$ & & $0,8 \pm 0,7$ & 0,16 & 0,29 & $-0,28$ & $-0,09$ \\
\hline & $\mathrm{H}+\mathrm{Al}^{3+}$ & & $6.1 \pm 3,1$ & 0.26 & 0,07 & $-0,46^{+}$ & 0,06 \\
\hline & \multirow{2}{*}{$\begin{array}{ll}\text { Soma } & \mathrm{d} \theta \\
\text { Bases } & \end{array}$} & & $2,1 \pm 1,9$ & 0,08 & $-0,43^{*}$ & 0,32 & $-0,12$ \\
\hline & & & $2,9 \pm 1,6$ & 0,16 & $-0,35$ & 024 & $-0,18$ \\
\hline & $\begin{array}{l}\text { CTC } \\
\text { CTC a pH } \\
7.0 \text { (T) }\end{array}$ & & $8,2 \pm 3,0$ & 0,32 & 0,19 & $-0,28$ & $-0,01$ \\
\hline & $\vee \%$ & \multirow[t]{2}{*}{$\%$} & $26,2 \pm 21,1$ & $-0,04$ & $-0,46^{\star}$ & $0,49^{*}$ & $-0,09$ \\
\hline \multirow{11}{*}{ 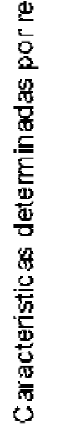 } & $m$ & & $36,5 \pm 29,7$ & 0,02 & $0,61^{*}$ & 0,35 & 0,04 \\
\hline & $\begin{array}{l}\text { Matéria } \\
\text { orĝ̣nica }\end{array}$ & $\mathrm{dg} \mathrm{kg}^{-1}$ & $3,0 \pm 1,2$ & 0,08 & $-0,26$ & 0,16 & $-0,23$ \\
\hline & $Z n$ & \multirow[t]{3}{*}{$\mathrm{mg} \mathrm{dm}$} & $2,93 \pm 5,33$ & 0.11 & 0,10 & $-0,07$ & $-0,35$ \\
\hline & $\mathrm{Fe}$ & & $82,9 \pm 44,7$ & 0,09 & 0,36 & $-0.44^{*}$ & $-0,12$ \\
\hline & $\mathrm{Mn}$ & & $25,0 \pm 25,5$ & 0,01 & 0,06 & 0,14 & $-0,43^{*}$ \\
\hline & $\mathrm{Cu}_{\mathrm{L}}$ & \multirow{4}{*}{$\%$} & $0,68 \pm 1,02$ & 0,19 & 0,13 & $-0,24$ & $-0,44^{*}$ \\
\hline & Areia & & $61,3 \pm 17,9$ & 0,06 & 0,04 & $-0,14$ & 0,13 \\
\hline & Silte & & $7 \pm 4$ & -0.07 & $-0,12$ & 0.36 & $-0,12$ \\
\hline & Argila & & $31,7 \pm 16,1$ & $-0,04$ & $-0,01$ & 0,06 & $-0,11$ \\
\hline & RFA & - & - & 0,11 & 0,30 & $-0,28$ & $-0,34$ \\
\hline & $\mathrm{NH}$ & - & - & $-0,28$ & $-0,39^{*}$ & - & - \\
\hline \multirow{3}{*}{ 高 } & A & - & - & $-0,16$ & $-0,17$ & - & - \\
\hline & $\mathrm{NN}$ & - & - & 0,15 & $-0,14$ & - & - \\
\hline & $\mathrm{NF}$ & - & - & $-0,33$ & $-0,01$ & - & - \\
\hline \multirow{3}{*}{ 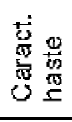 } & $\mathrm{DC}$ & - & - & $-0,33$ & 0,22 & - & - \\
\hline & $P R$ & - & - & $-0,35$ & $-0,13$ & - & - \\
\hline & $\mathrm{AF}$ & - & - & $-0,40^{*}$ & 0,02 & - & - \\
\hline \multirow{3}{*}{ 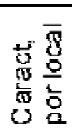 } & Lat & - & - & 0,10 & -0.26 & 0,04 & 0,05 \\
\hline & Long & - & - & 0,06 & $-0,23$ & $-0,01$ & $-0,11$ \\
\hline & Alt & - & - & 0,31 & 0,25 & -0.26 & $-0,55^{\star}$ \\
\hline
\end{tabular}

*- significativos a $5 \%$ de probabilidade pelo teste t. ${ }^{1}-\mathrm{dp}$ : desvio padrão. 
observadas são apresentadas na Tabela 2.

Estudos em condições controladas poderão apontar, com grande precisão, as complicadas inter-relações entre os nutrientes analisados e destes com as características morfológicas e fitoquímicas de interesse. Observações feitas por Torres (1972) mostram o registro de $\mathrm{pH}$ entre 4,5 e 5, e pobreza em $\mathrm{P}$ e K nos solos da América Central, em locais de ocorrência da poaia, verificando-se aproximação comos dados observados no Tabela 3.

A textura dos solos das reboleiras foi predominantemente argilosa à média, o que está de acordo com o observado por Torres (1972), embora muitos autores indiquemque a poaia ocorra com maior freqüência em solos arenosos (Pinto, 1972).

\section{Caracterização da morfologia e porcentagem de radiação fotossinteticamente ativa \\ As características das reboleiras ou} acessos quanto à morfologia, teores de emetina $\mathrm{e}$ de cefelina, foram determinados em amostras representadas por uma ou mais hastes por reboleira. As demais características (número de hastes, comprimento e largura, além da porcentagem fotossinteticamente ativa ou de fluxo de fótons fotossintéticos) foramtomadas em relação à reboleira. O comprimento da parte aérea ou altura das hastes foi de 5 a 38,2 cm, mostrando amplitude bem menor do que aquela observada por Assis (1992), que observou alturas entre 11,5 e $59 \mathrm{~cm}$ em exsicatas coletadas na Mata Atlântica. Cerca de 57\% das hastes coletadas apresentaram altura inferior a 20 $\mathrm{cm}$. Aárea foliar foi a única característica, dentre as utilizadas para calcular as correlações, que apresentou correlação significativa e negativa como teor de cefelina, indicando que fatores que favorecem aumento da área foliar podem reduzir os teores de cefelina. Aárea foliar média por haste foi de $146 \mathrm{~cm}^{2}$. Cerca de $84 \%$ das hastes amostradas apresentaram menos que $2 \mathrm{~g}$ de raízes secas, sendo que esta característica foi negativamente correlacionada com a altitude (Tabela 2 ).

O comprimento, em $65 \%$ das reboleiras, foi inferior a $2 \mathrm{~m}$, enquanto que a largura em $85 \%$ destas foi também inferior a $2 \mathrm{~m}$, sendo que as dimensões médias das reboleiras foram aproximadamente 1,8 x 1,3 m. Foi observada a ocorrência de flores brevistilas nos acessos ITA-2, UNA-1 e CAT-2, sendo que, ITA-1, CAT-1 e CAT-3, nas mesmas populações, e POL-1, MUR-1, EUG1, CON-1 a 3, MAR-1 a 2, CAR-1 a 3 e IRU-1, apresentaram flores longistilas. Nos demais acessos não foram observados flores para fazer a distinção.

Aporcentagemda radiação fotossinteticamente ativa ou, mais precisamente, a porcentagem do fluxo de fótons fotossintéticos, medido sobre as reboleiras, variou entre 0,14 e $17 \%$, sendo que $69 \%$ das reboleiras apresentaram porcentagens inferiores a $5 \%$. Na poaia, apesar das plantas perderem todas as folhas sob luz plena, como observado pelos poaeiros nas florestas subcaducifólias (Pinto, 1972), as diversas experiências de cultivo têm mostrado que a planta tem boa produção de matéria seca sob sombreamento de apenas 50\% (Lameira et al., 1998) a 75\% (Torres, 1972), indicando capacidade de adaptação a outros ambientes.

\section{Caracterização química}

Em cerca de $65 \%$ das amostras de raízes analisadas foram observados teores de emetina entre 1 e $2 \%$, sendo que em $15 \%$ das amostras foram superiores a $2 \%$. O teor de cefelina, em $61 \%$ das amostras, foi inferior a 0,3\%. Na Tabela 3 estão apresentados os acesso com as respectivas médias e desvios padrão de: teor de cefelina, de emetina, de emetina somada com cefelina e a relação entre os teores de cefelina e de emetina (C/E). Na literatura consultada observa-se grande variação nos teores de emetina/cefelina, conforme a origem da poaia ou ipeca (Addor, 1945; Pinto, 1972; Gupta et al., 1986; Sahu \& Mahato, 1982; Yoshimatisu et al., 1994). As reboleiras com maior teor de cefelina e emetina somados $(\mathrm{C}+\mathrm{E})$ foram, quase sempre, aquelas com maior teor de emetina.

A drástica alteração na relação cefelina/ emetina caracteriza dois produtos comerciais: a ipeca de Cartagena e do Rio. Apesar do material estudado ser muito semelhante ao da "Ipeca do Rio", quanto aos teores de cefelina e emetina (C/ $\mathrm{E}<1$ ), cerca de $7 \%$ das amostras apresentaram teor de cefelina superior ao de emetina ( $C / E>1)$. Estas amostras foram únicas em cada um dos acessos: UNA-2, ITA-3, ITA-1 e VRB-3, sendo necessários mais estudos para determinar as causas desta variação.

As observações realizadas nas amostras e os resultados da análise de correlações para cada um dos acessos (UNA-1 e ITA-1) foram resumidos na Tabela 4. A variação nos teores dos alcalóides e também nas características morfológicas foi similar entre os dois acessos. Observa-se a grande variação no teor de emetina e de cefelina na mesma raiz. As correlações só foram significativas no acesso ITA-1. A maior espessura da raiz não indicou altos teores de alcalóides, mas sim o aumento na proporção da matéria seca da raiz, em função do crescimento secundário, é que foi altamente correlacionado como teor de alcalóides sendo que a porcentagem em peso do cilindro central (PPCC) apresentou correlação significativa e positiva com 
TABELA 3. Teores de cefelina $(C)$, de emetina $(E)$ e de cefelina+emetina $(C+E)$ e a relação cefelina/emetina em 27 acessos de poaia (Psychotria ipecacuanha) coletados nos estados: MT, RJ, ES, MG e BA.

\begin{tabular}{|c|c|c|c|c|}
\hline \multirow[t]{2}{*}{ Acessos } & \multicolumn{4}{|c|}{ Caracteristicas (média \pm des vio padräo) } \\
\hline & $\mathrm{C}(\%)$ & $E(\%)$ & $\mathrm{C}+\mathrm{E}(\%)$ & $\mathrm{C} / \mathrm{E}$ \\
\hline CAR -1 & $0,41 \pm 0,14$ & $2,40 \pm 0,05$ & $2.81 \pm 0.09$ & $0.17 \pm 0,06$ \\
\hline CAR -2 & $0,30 \pm 0,04$ & $2,12 \pm 0,42$ & $2: 42 \pm 0: 45$ & $0,14 \pm 0,02$ \\
\hline CAR-3 & $0,47 \pm 0,14$ & $1,18 \pm 0,42$ & $1: 65 \pm 0: 17$ & $0,40 \pm 0,11$ \\
\hline CAT-1 & $0,20 \pm 0,10$ & $2,10 \pm 0,39$ & $2: 29 \pm 0: 49$ & $0.09 \pm 0.03$ \\
\hline CAT-2 & $0,10 \pm 0,04$ & $1,43 \pm 0,07$ & $1,52 \pm 0,03$ & $0,07 \pm 0,03$ \\
\hline CAT-3 & $0,65 \pm 0,72$ & $1,67 \pm 0,33$ & $2: 31 \pm 0,03$ & $0.39 \pm 0.34$ \\
\hline CON-1 & $0,22 \pm 0,00$ & $1,42+0,40$ & $1: 64 \pm 0: 40$ & $0,16 \pm 0,04$ \\
\hline CON-2 & $0,09 \pm 0,03$ & $1,33 \pm 0,35$ & $1: 42 \pm 0: 37$ & $0,07 \pm 0,00$ \\
\hline CON-3 & $0,14 \pm 0,05$ & $2,20 \pm 0,14$ & $2,34 \pm 0,09$ & $0,06 \pm 0,03$ \\
\hline EUG-1 & $0,12 \pm 0,02$ & $1,23 \pm 0,05$ & $1,34 \pm 0,02$ & $0.09 \pm 0,02$ \\
\hline IRU-1 & $0,62 \pm 0,27$ & $1,40 \pm 0,61$ & $2.02 \pm 0.82$ & $0,44 \pm 0,22$ \\
\hline ITA-1 & $0,22 \pm 0,19$ & $0,46 \pm 0,29$ & $0,68 \pm 0,32$ & $0,48 \pm 0,80$ \\
\hline ITA-2 & $0,27 \pm 0,21$ & $1,30 \pm 0,25$ & $1,57 \pm 0,12$ & $0.21 \pm 0,23$ \\
\hline ITA-3 & $0,26 \pm 0,05$ & $1,03 \pm 0,72$ & $1.29 \pm 0.69$ & $0,25 \pm 0,56$ \\
\hline MALI-1 & $0,28 \pm 0,08$ & $0,92 \pm 0,75$ & $1: 20 \pm 0,69$ & $0,31 \pm 1.12$ \\
\hline MAC-1 & $0,44 \pm 0,25$ & $1,31 \pm 0,33$ & $1,75 \pm 0.56$ & $0,34 \pm 0,12$ \\
\hline MAR-2 & $0,10 \pm 0,03$ & $1,43 \pm 0,04$ & $1,53 \pm 0,06$ & $0.07 \pm 0.02$ \\
\hline MUR-1 & $0,54 \pm 0,38$ & $0,99 \pm 0,40$ & $1,53 \pm 0,66$ & $0,55 \pm 0,30$ \\
\hline POL-1 ${ }^{1}$ & 0.18 & 2,48 & 2,66 & 0,072 \\
\hline UNA-1 & $0,20 \pm 0,08$ & $1,29 \pm 0,26$ & $1,49 \pm 0,30$ & $0.15 \pm 0,06$ \\
\hline UNA-2 & $0,51 \pm 0,36$ & $1,24 \pm 0,57$ & $1,74 \pm 0: 45$ & $0.41 \pm 0.49$ \\
\hline VRB-1 ${ }^{1}$ & 0.42 & 1,36 & 1,78 & 0.31 \\
\hline VRB-2 ${ }^{1}$ & 0.14 & 1,70 & 1,84 & 0.08 \\
\hline VRB-3 & $0,81 \pm 0,97$ & $1,25 \pm 0,37$ & $2,07 \pm 060$ & $0.65 \pm 1.01$ \\
\hline VRB-4 & $0,34 \pm 0,16$ & $1,34 \pm 0,72$ & $1: 68 \pm 0: 75$ & $0.25 \pm 0.24$ \\
\hline VRB-5 & $0,28 \pm 0,13$ & $1,17 \pm 0,52$ & $1,45 \pm 0,59$ & $0.24 \pm 0.16$ \\
\hline
\end{tabular}

1 - não foi calculado o desvio padrão, pois a amostra constou de apenas uma haste

TABELA 4. Variação e correlações simples das características morfológicas (diâmetro externo da raiz) - DER, diâmetro do cilindro central - DCC e porcentagem em peso do cilindro central - PPCC) e químicas (teores de emetina - E, de cefelina-C,) das raízes de dois acessos de poaia (Psychotria ipecacuanha).

\begin{tabular}{|c|c|c|c|c|c|c|}
\hline \multirow[t]{3}{*}{ Caracteristicas } & \multicolumn{6}{|c|}{ Acessos } \\
\hline & \multicolumn{3}{|c|}{ ITA-' $(n=19)$} & \multicolumn{3}{|c|}{ UNA-1 } \\
\hline & Média \pm desvio padrăo & C & $E$ & Média desvio padrăo & C & $E$ \\
\hline DER (mm) & $5,13 \pm 0,78$ & $-C .40$ & 0,22 & $4,04 \pm 0,85$ & 0,20 & 0,25 \\
\hline $\mathrm{DCC}(\mathrm{mm})$ & $1,18 \pm 0,18$ & 0,10 & $0,63^{*}$ & $1,05 \pm 0.26$ & 0,27 & 0,42 \\
\hline $\operatorname{PPCC}(\%)$ & $1,27 \pm 0,20$ & $0,84^{*}$ & 0,44 & $1,01 \pm 0.29$ & 0,04 & 0,36 \\
\hline $\mathrm{C}(\%)$ & $0.18 \pm 0.05$ & - & - & $0.16 \pm 0.08$ & - & - \\
\hline$E(\%)$ & $1.27 \pm 0.20$ & - & - & $1.01 \pm 0.29$ & - & - \\
\hline
\end{tabular}

* - significativo pelo teste $t$ a $5 \%$ de probalidade

Rev. Bras. PI. Med., Botucatu, v.11, n.1, p.24-32, 2009. 
o teor de cefelina e, o diâmetro do cilindro central (DCC) com E.

\section{Análise das características morfológicas e químicas pela técnica de componentes principais \\ Os resultados da análise das características morfológicas (número de folhas, número de nós, altura ou comprimento da haste, peso da raiz, número de hastes por reboleira) e químicas (teores de cefelina e de emetina) por meio da técnica de componentes principais são apresentados nos Tabela 5. \\ Os resultados obtidos com a técnica de componentes principais são pouco informativos sobre}

a diversidade genética, uma vez que se trata de dados fenotípicos obtidos de genótipos sob pressões ambientais diferentes (coletas emépocas diferentes). Porém, a técnica permitiu o agrupamento de acessos do estado do Rio de Janeiro, de Minas Gerais (MAR) e outro da Bahia (UNA-1). Noutro grupo estariam acessos de MG, além de acessos do Espírito Santo (IRU-1) e da Bahia (UNA-2). A separação entre os acessos UNA-1 e UNA-2 ocorreu em virtude da diferença, principalmente morfológica, entre os dois, o primeiro apresentando haste em grande número e com grande comprimento e maior número de folhas, além de raízes mais numerosas e com maior peso

TABELA5. Estimativas das variâncias (autovalores -AVA), associadas aos componentes principais (CP) e respectivos coeficientes de ponderação (autovetores - AVE) das características teores de cefelina $(C)$ e de emetina $(E)$, número de hastes por reboleira $(\mathrm{NH})$, altura $(\mathrm{A})$, número de nós $(\mathrm{NN})$, número de folhas $(\mathrm{NF})$ e peso de raízes secas (PR) determinados em 26 acessos de poaia (Psychotria ipecacaunha).

\begin{tabular}{lll|l|lll|l|l|l}
\hline CP & \multicolumn{2}{c|}{ Variância } & \multicolumn{5}{c}{ Coeficientes de ponderação associados às caracteristicas - AVE } \\
\hline 1 & AVA & $\%$ & C & E & NH & A & NN & NF & PR \\
\hline 2 & 2,47 & 35,23 & $-0,344$ & $-0,191$ & 0,423 & 0,474 & $-0,038$ & 0,425 & 0,510 \\
\hline 3 & 1,30 & 18,52 & $-0,466$ & 0,669 & -0178 & $-0,196$ & $-0,474$ & 0,186 & 0,076 \\
\hline 4 & 1,26 & 18,05 & 0,068 & 0,268 & -0538 & 0,205 & 0,518 & 0,454 & 0,069 \\
\hline 5 & 0,69 & 9,89 & 0,727 & 0,288 & 0,026 & 0,424 & $-0,432$ & 0,145 & 0,029 \\
\hline 6 & 0,58 & 8,32 & $-0,186$ & 0,487 & 0,341 & 0,474 & 0,322 & $-0,471$ & $-0,250$ \\
\hline 7 & 0,48 & 6,89 & 0,236 & 0,252 & 0,075 & $-0,301$ & 0,205 & $-0,358$ & 0,784 \\
\hline
\end{tabular}

total. O acesso VRB-3 se destacou dos demais pelo pequeno porte e pela alta relação cefelina/emetina.

A análise dos dados possibilita o descarte de características cuja variaçãoé pequenae, também, aquelas altamente correlacionadas entre si. Assim, não foram utilizadas as características diâmetro do caule e área foliar. Também a características número de folhas é de fácil determinação se comparada com a área foliar, que necessita das medidas do comprimento e da largura da folha ou da mediação direta em equipamento adequado.

\section{CONCLUSÃO}

Os resultados obtidos neste trabalho permitiram chegar às seguintes conclusões principais:

- a poaia ocorreu com maior freqüência em locais entre 200 e $600 \mathrm{~m}$ de altitude, com precipitações anuais de $1250 \mathrm{~mm}$, em fragmentos da Floresta Estacional Semidecidual, sob baixa proporção da radiação fotossiteticamente ativa, em solos distróficos a álicos com textura média a argilosa;

- a maior fertilidade do solo favoreceu a ocorrência de reboleiras maiores, mas com tendência de redução no teor de emetina nas raízes;

- os teores dos alcalóides cefelina e emetina assim como a relação entre eles, inferior a um, permitiram incluir o material amostrado na categoria "Ipeca do Rio".

\section{REFERÊNCIA}

ADDOR, A.A. Considerações acerca da poaia. Boletim do Ministério da Agricultura, v.34, p.1-18, 1945.

ASSIS, M.C. Aspectos taxonômicos, anatômicos e econômicos da "ipeca" Psychotria ipecacuanha(Brot.) Stokes (Rubiaceae). 1992.132p. Dissertação (Mestrado) - Universidade de São Paulo, São Paulo. CHRISTIANSEN, J.L.; RAZA, S.; ORTIZ, R. White lupin (Lupinus albus L.) germplasm collection and preliminary in situ diversity assesment in Egypt. Genetic Resources and Crop Evolution, v.46, p.169-74, 1999.

COSTA, A.F. Farmacognosia. 2.ed. Lisboa: Calouste Gulbenkian, 1978. p.614-24. 
FIGUEIREDO, L.S. Germinação e crescimento de Tanacetum vulgare (L.) Schultz Bip. 1998. 62p. Dissertação (Mestrado) - Departamento de Fitotecnia, Universidade Federal de Viçosa, Viçosa - MG.

GUPTA, M.P. et al. Seasonal variation in the alkaloidal content of Panamanian Ipecac. Fitoterapia, v.57, n.3, p.147-51, 1986.

INSTITUTOBRASILEIRODE GEOGRAFIAE ESTATÍTICA. Mapa de vegetação do Brasil. Rio de Janeiro: IBGE, 1993.. Escala 1:5.000.000.

LAMEIRA, O.A. et al. Cultivo de Psychotria ipecacuanha Stokes. In: SIMPÓSIO DAS PLANTAS MEDICINAIS DO BRASIL, 15., 1998, Águas de Lindóia (SP). Resumos... São Paulo:UNIFESP, 1998. p.111.

MAXTED, N.; PAINTING, K.; GUARINO, L. Ecogeographic surveys: training materials. International Plant Genetic Resouces Institute. Itália: IPGRI, 1997. 54p. Disponível em <http://www.cgiar.org/ipgri/TRAINING/5-2/index. htm.>. Acesso em: 18 jan. 2000.

NIMER, E. Climatologia do Brasil. Rio de Janeiro: IBGE, 1989. 422p.

OLIVEIRA, L.O.; MARTINS, E.R. O desafio das plantas medicinais brasileiras: I - o caso da poaia (Cephaelis ipecacuanha). Campos dos Goytacazes: UENFFENORTE, 1998.73p.
PINTO, C.M.D. A ipecacuanha. In: SIMPÓSIO INTERNACIONAL SOBRE PLANTAS DE INTERESSE ECONÔMICO DE LAFLORAAMAZÔNICA, 1972, Belém (PA). Resumos... Belém:IICA, 1972.p.109-19.

SAHU, N.P.; MAHATO, S.B. Determination of emetine and cephaeline in ipecac roots by high-performance liquid chromatography. Journal of Chromatography, v.238, p.525-9, 1982.

SOUSA, M.P. et al. Constituintes químicos ativos de plantas medicinais brasileiras. Fortaleza:EUFC, 1991. 416p.

TORRES, L.A.C. Contribuicion al conocimiento de la Cephaelis ipecacuanha (Brot.) A. Rich., com especial referencia a Colombia. In: SIMPOSIO INTERNACIONAL SOBRE PLANTAS DE INTERESSE ECONÔMICO DE LA FLORA AMAZÔNICA, 1972, Belém (PA). Resumos... Belém:IICA, 1972. p.123-36.

VELOSO, H.P. As condições ecológicas de Cephaelis ipecacuanha Rich. Memória do Instituto Oswaldo Cruz, v.45, n.2, p.361-72, 1947

YOSHIMATSU, K.; AOI, K.; SHIMOMURA, K. Clonal propagation of Cephaelis ipecacuanha (II): Characteristics of regenerated plants field cultivated in two districts. Journal Plant Physiology, v.144, p.22-5, 1994. 